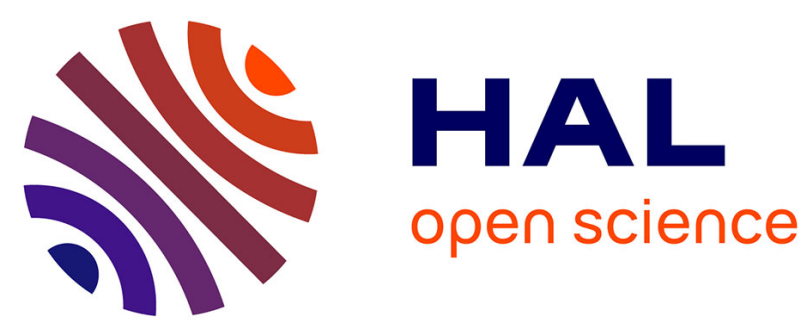

\title{
Strategic Supply Chain Planning and Risk Management: Experiment of a Decision Support System Gathering Business Departments Around a Common Vision
} Raphaël Oger, Matthieu Lauras, Frederick Benaben, Benoit Montreuil

\section{- To cite this version:}

Raphaël Oger, Matthieu Lauras, Frederick Benaben, Benoit Montreuil. Strategic Supply Chain Planning and Risk Management: Experiment of a Decision Support System Gathering Business Departments Around a Common Vision. 8th International Conference on Industrial Engineering and Systems Management (IESM 2019), Sep 2019, Shanghai, China. p. 306-311, 10.1109/IESM45758.2019.8948116 . hal-02384806

\section{HAL Id: hal-02384806 \\ https://imt-mines-albi.hal.science/hal-02384806}

Submitted on 20 Dec 2019

HAL is a multi-disciplinary open access archive for the deposit and dissemination of scientific research documents, whether they are published or not. The documents may come from teaching and research institutions in France or abroad, or from public or private research centers.
L'archive ouverte pluridisciplinaire HAL, est destinée au dépôt et à la diffusion de documents scientifiques de niveau recherche, publiés ou non, émanant des établissements d'enseignement et de recherche français ou étrangers, des laboratoires publics ou privés. 


\section{Strategic Supply Chain Planning and Risk Management: Experiment of a Decision Support System Gathering Business Departments Around a Common Vision}

\author{
Raphaël Oger \\ Centre Génie Industriel, \\ IMT Mines Albi, \\ Toulouse University \\ Albi, France \\ raphael.oger@mines- \\ albi.fr
}

\author{
Matthieu Lauras \\ Centre Génie Industriel, \\ IMT Mines Albi, \\ Toulouse University \\ Albi, France \\ matthieu.lauras@mines- \\ albi.fr
}

\author{
Frédérick Benaben \\ Centre Génie Industriel, \\ IMT Mines Albi, \\ Toulouse University \\ Albi, France \\ frederick.benaben@mi \\ nes-albi.fr
}

\author{
Benoit Montreuil \\ Physical Internet Center, \\ ISYE School, Georgia \\ Institute of Technology \\ Atlanta, U.S.A. \\ benoit.montreuil@isye.g \\ atech.edu
}

\begin{abstract}
Strategic supply chain planning and supply chain risk management are two fields of supply chain management that are inseparable nowadays. The ability to consider risks is essential to maintain business performance. In addition, integrating the different business departments' visions in a common business vision is necessary to properly plan the future of a company. However, it is still a challenge for companies to design and maintain a decision-making process supporting strategic supply chain decisions that integrates risk management and unify business vision across departments. This paper relates an industrial experiment as an attempt to meet this challenge. This experiment was asked by a pharmaceutical company with the aim of supporting strategic decisions regarding its network of suppliers. It led to a decision-making process including the use of a computerized information system composed of a software for computations and a business intelligence software to easily make decisions. This process was put in practice on a pilot use case with two years old data. It resulted in the identification of several decisions that could have been made if the process was in operation two years ago, which is considered as a first validation of the approach. Finally, limitations have been identified regarding the data collection, opening avenues for future research on an innovative approach combining supply chain hyperconnectivity and event-driven principles.
\end{abstract}

Keywords - Strategic Supply Chain Planning; Supply Chain Risk Management; Decision Support Systems; DecisionMaking Process; Business Visions Unification.

\section{INTRODUCTION}

\section{A. Strategic Supply Chain Planning}

Companies trying to have a long-term vision and control over their business define strategic objectives which must be challenged to ensure their reachability. Challenging the reachability of strategic objectives means challenging the ability of reaching a performance in line with these objectives; performance which depends on the cumulative outcomes of activities performed by the company and costs of the means involved. Knowing that performing activities takes time implies that they must be anticipated to obtain their outcomes at a desired point in time. In addition, performing activities requires resources (e.g. people, equipment, money, material, and license), so the set of activities performed is limited by the available resources. If a company wants to perform a set of activities cumulatively requiring more resources than it owns, it must acquire additional resources. This acquisition activity also requires time and resources and so anticipation. This need for anticipation of activities results in the establishment of planning processes. These planning processes aim to decide the sequence of future activities that will enable the achievement of the desired outcomes at the desired point in time. Finally, this paper specifically focuses on industrial companies and their supply chains, and on activities requiring an anticipation of several months or years (e.g. setting up a new production line, a new partnership, designing a new product, or building a new plant). In these circumstances, the planning process is named "strategic supply chain planning", with "strategic" standing for longterm anticipation [1].

\section{GATHERING DEPARTMENTS TOGETHER AROUND A COMMON VISION OF THE COMPANY}

The activities to plan concern all companies' departments (e.g. manufacturing, sales, supply, purchasing, marketing, finance, product development, performance improvement, and human resources). They all have an impact on the business performance and are all correlated when considering the company in its entirety. Each decision made by a department has an impact on all departments, even if sometimes negligible. For example, a decision of starting an advertising campaign will have a direct impact on sales and revenues, and on the manufacturing, transportation, distribution and supply activities. But it can also indirectly impact performance improvement and human resources departments if it implies decisions regarding production capacity increase. In addition, departments usually have their own objectives which can be antagonistic between departments when considering a global vision of the company. Therefore, there is a need for a common vision of the company's performance across departments [1]. A vision that will enable decision-making processes to prioritize strategic supply chain decisions considering the overall company's performance rather than departmentspecific visions.

\section{A. Risk Management}

According to the ISO standard on risk management vocabulary [2], uncertainty is "the state, even partial, of deficiency of information related to, understanding or 
knowledge of an event, its consequence, or likelihood." If a company could know with certainty the future of its external environment and the outcomes of each activity it can perform, there would be only one possible outcome for each possible strategic supply chain plan. However, even if it can sometime be reduced, uncertainty is unavoidable. This uncertainty creates the eventuality that a plan based on a deterministic forecast of the future do not lead to the achievement of the expected outcomes [3].

The ISO standard on risk management guidelines [4] defines the risk as the "effect of uncertainty on objectives", with an effect defined as "a deviation from the expected". In the case of supply chain planning, considering the objective as the expected outcome of the supply chain plan in terms of performance (any performance criterions could be considered), the existence of a risk can be defined as the following: a risk exists if there is an eventuality that the actual outcome will be different from expected outcome. And it can be described by the following characteristics: a measure of the deviation between the actual and expected outcome, its likelihood, and potentially its cause (event that would lead to the deviation, if it can be identified).

Finally, the ISO standard on risk management vocabulary [2] defines risk management as the "coordinated activities to direct and control an organization with regard to risk". Therefore, this definition in the context of strategic supply chain planning can be adapted as the following: coordinated activities to direct and control supply chains with regard to risk on a long-term horizon. This definition in the overall context of supply chain management leads to the term Supply Chain Risk Management (SCRM) [5].

\section{B. Supply Chain Planning and Risk Management: A Decisive Combination That Misses Practical Solutions}

The studies undertaken by Bhatnagar and Sohal [6] and by Oliveira et al. [5] strengthen the idea that if not considered beforehand, "uncertainty has a significant negative effect on supply chain performance" [6]. It confirms the importance of considering it when planning supply chains. Oliveira et al. [5] undertook a systematic literature review about Supply Chain Risk Management (SCRM), with regards to the ISO standard on risk management principles and guidelines [7], and inferred a process for carrying out SCRM. However, to the best of authors knowledge and findings, the Decision Support Systems (DSS) available in the literature do not satisfactorily enable to consider uncertainty and risks when planning supply chains [8]-[11]. Several Supply Chain Risk Management (SCRM) reviews insist on the need for practical information system solutions to be implemented within the industry [12]-[14]. Prakash et al. [13] insist on the lack of research on information system implementation for managing risks in supply chains. Therefore, there would be a clear benefit for companies to find solutions to effectively consider uncertainty and risks when making decisions about supply chain plans.

\section{Paper Objectives and Structure}

This paper aims to share the results of an industrial experiment regarding risk management in the context of strategic supply chain planning. The experiment had two objectives: the first was to validate the applicability and benefits of an approach of strategic supply chain planning with regards to risk management. The studied approach was introduced by Oger et al. [15], [16]. The second objective was to highlight major research avenues for both academics and practitioners.

This first section introduced the main concepts to understand the context of the experiment. The second section introduces the industrial issue explaining the interest for the experiment as well as the use case. The third section describes the experiment methodology as well as the results. Finally, the fourth section discusses the results and avenues for future research.

\section{INDUSTRIAL ISSUE AND USE CASE}

This experiment has been undertaken with is a cosmetics company. This section introduces the use case chosen for the experiment.

\section{A. Industrial Issue and Objective}

Few years ago, the company suffered a major disruption that impacted the business for several years. One of its main suppliers decided to stop its production activity within few weeks after the announcement. Still today, pronouncing the name of this supplier has an effect with employees, reminding strong memories. From the business viewpoint, this event is the origin of the chosen use case described in the following subsection. The main objective for the company is to prevent this type of situation to happen again. More generally, it is to minimize the impact major disruptions regarding its supply network can have on the company's performance. This objective can be rephrased as follow: to maximize the robustness of the company regarding its supply network. Considering the definition of robustness given by Brandon-Jones et al. [17] that was highlighted by [18]: "the ability of a supply chain to withstand disruption and continue operating".

\section{B. Use Case}

A family of packaging component (bottles) has been selected to be the pilot for the experiment. The objective is to challenge the robustness of the supply network of bottles in terms of production capacity and its impact on the company's financial performance. This family has been decomposed into 103 sub-families of bottles, grouping bottles references by bill-of-material and routing similarities. The 26 main sub-families corresponding to 75 percent of the annual volume of supplied bottles have been included in the experiment. The first-tier supply network of bottles is considered and contains 6 suppliers for the 26 sub-families. To be able to challenge the capacity of the supply network, information about the equipment required to produce the bottles has been considered. It is composed of 53 equipment including the following: 10 machines of 2 different types, and 43 molds (that must be mounted on the machines) of 26 different types. From the decision-making viewpoint, the experiment includes the company's departments, stakeholders, and decision levers described in Table 3.

\section{EXPERIMENT}

The experiment was composed of two phases: first the technological implementation of the approach introduced by Oger et al. [16]. It resulted in an information system 
composed of a software developed in Python ${ }^{\mathrm{TM}}$ coupled with an existing business intelligence software called Tableau $^{\circledR}$ [19] (Figure 1). The second phase was the industrial experiment consisting of the design and execution of a decision-making process taking advantage of the technological implementation. This paper focuses on the industrial experiment so only this second phase is described in the rest of the paper.

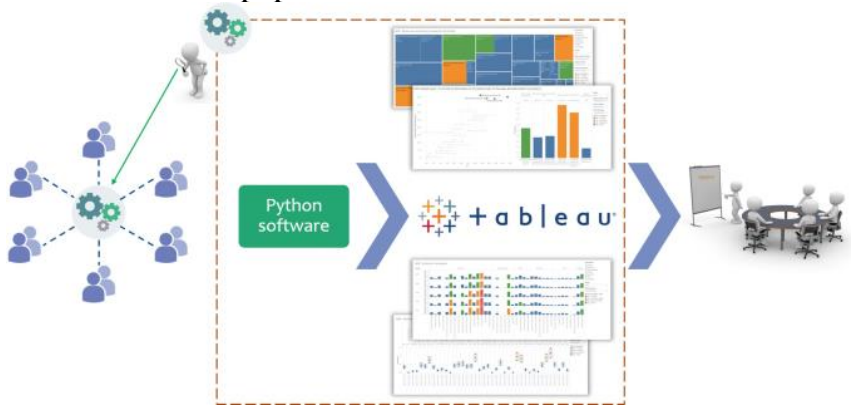

Figure 1: information system designed including the python software based on the approach introduced by Oger et al. [16]

\section{A. Decision-making Process Creation}

The created decision-making process contains two phases: design and execution. They are described in the next subsections and illustrated with Figure 4.

\section{1) Design of the "Design" phase}

The design of the decision-making process has been designed so it can be used as an operational procedure to update the execution phase according to feedbacks - and not only as a one-time design.

\section{a) Data and stakeholders}

The first part of the design phase is about defining data and stakeholders required to perform the decision-making process. It includes defining the following:

- types of data to gather that describe the actual strategic supply chain plan and corresponding stakeholders or information systems responsible for providing the data, decision levers related to the strategic supply chain plan and corresponding decision makers,

- time horizon and granularity (i.e. period length) on which the data are collected,

- a process manager responsible for overseeing the smooth running of the decision-making process.

\section{b) Dashboards and key performance indicators}

The second part of the design phase is about defining relevant Key Performance Indicators (KPIs) and dashboard to support the decisions. It includes defining the following:

- KPIs that can be generated from the results of the analysis performed by the Python ${ }^{\mathrm{TM}}$ software. The objective is to provide decision makers with consolidated information improving their ability to make relevant decision.

- Dashboards based on the defined KPIs, with the objective of enabling a smooth decision-making meeting.

\section{2) Design of the "Execution" phase}

The execution phase has been designed to structure the operational part of the decision-making process and guide stakeholders involved (Figure 4). It is composed of two steps: first the decision-making meeting preparation, and second the decision-making meeting itself.

\section{a) Decision-making meeting preparation}

The decision-making meeting preparation aims to enable an effective and efficient decision-making meeting. The meeting preparation consists of the following activities:

- gathering data according guidelines defined during the design phase,

- running the python software based on the gathered data, - analyzing results according to the dashboards defined during the design phase, and if needed going back to the previous activities to adjust elements,

- preparing recommendations to ensure a smooth, effective, and efficient decision-making meeting. It especially includes organizing the dashboards.

\section{b) Decision-making meeting}

The decision-making meeting aims to generate a consensus, between decision makers from each department, about the strategic supply chain plan to implement. It is composed of the following activities inspired from $\mathrm{MG}$ Taylor Corporation [20]:

- Scan: scan the dashboards to identify weaknesses within the supply network.

- Focus: identify and compare the strategic supply chain plan alternatives that could enable to overcome the identified weaknesses (an alternative should be understood as a set of decisions forming a different plan than the current one). The objective is to define the one that seems to be the best compromise for the company.

- Act: decide the strategic supply chain plan to implement.

- Feedback: provide feedback on the current execution phase iteration to decide if there is an improvement opportunity justifying the run of a new iteration of the design phase. If not, only a new iteration of the execution phase must be started.

\section{B. Decision-making Process Run}

After creating the decision-making process design and execution phases (Figure 4), both phases have been run for the experiment.

\section{1) Design phase run}

The first step of the design phase was to define data required for the robustness analysis. It included the identification of the data about the current plan and the decisions levers having an impact on the considered data (Table 3). More details about the current plan data were given in the previous section describing the use case. For the strategic supply chain planning purpose, it has been decided to consider a time horizon of 5 years with a granularity of a year (i.e. one-year periods).

The second step of the design phase was to define the stakeholders to involve in the process. It includes departments and stakeholders providing data as well as making the decisions (Table 3). All mentioned stakeholders were part of the decision-making meeting. The Sales and Operation Planning manager (S\&OP manager) from the operations department has been chosen as the manager of the strategic supply chain planning decision-making process.

The third and last step of the design phase was to define KPIs, dashboards, and the meeting structure to effectively and efficiently support decisions about the 
company's supply network. Three main KPI categories have been defined: resource utilization, financial, and a combination of both named criticality. The objective of each of the category is described in Table 1. For each of these categories the main KPI was respectively: load versus capacity ratio, income relying on it, and income loss in case of breakage.

Table 1: categories of KPIs with their respective objective

\begin{tabular}{ll}
\hline KPI category & \multicolumn{1}{c}{ Objective } \\
\hline $\begin{array}{l}\text { Resource } \\
\text { utilization }\end{array}$ & $\begin{array}{l}\text { To challenge the ability of the company's supply } \\
\text { network to supply bottles in the right quantities. }\end{array}$ \\
\hline Financial & $\begin{array}{l}\text { To compare strategic supply chain plans in terms } \\
\text { of financial performance. }\end{array}$ \\
\hline Criticality & $\begin{array}{l}\text { To evaluate the financial risk related to the } \\
\text { breakage of a mold at a supplier. }\end{array}$ \\
\hline
\end{tabular}

Each KPI resulting from the Python ${ }^{\mathrm{TM}}$ software are at the lowest level of detail being the equipment itself. Then, they have been used to create dashboards within Tableau ${ }^{\circledR}$, some using the lowest level of details, and others aggregating KPIs according to the three dimensions described in Table 2. KPI aggregation must be understood as the combination of a specific KPI over several element of the same type (i.e. all having this KPI). For example, the criticality KPI used in the dashboard of Figure 2 is a network aggregation of resource utilization and financial KPIs over all molds of the supply network. The objective of this dashboard is to compare mold categories in relation to the financial loss that would be caused by the breakdown of a mold.

Equipment Category Criticality (ordinate) Vs Revenue (abscissa) Vs Saturation (color)

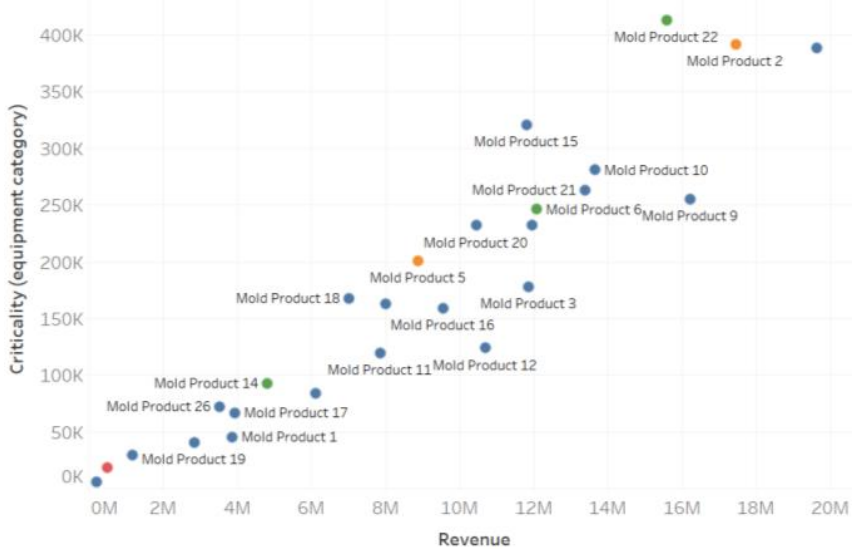

Figure 2: dashboard highlighting the criticality of equipment categories regarding the financial loss that would be caused by the breakdown of a mold

Table 2: three dimensions used to aggregate KPIs to create dashboards giving a high-level vision

\begin{tabular}{ll}
\hline $\begin{array}{c}\text { Dimension of } \\
\text { KPI aggregation }\end{array}$ & \multicolumn{1}{c}{ Description } \\
\hline Network & $\begin{array}{l}\text { Aggregation over several structural element } \\
\text { of the supply chain network (e.g. equipment } \\
\text { per supplier). }\end{array}$ \\
\hline Time & Aggregation over several time periods. \\
\hline Scenario & $\begin{array}{l}\text { Aggregation over several scenarios of } \\
\text { potential futures. }\end{array}$ \\
\hline
\end{tabular}

Finally, it has been decided to involve all stakeholders of Table 3 in the decision-making meeting. The meeting duration was fixed to two hours plus one hour to debrief the experiment: one hours for the scan phase, thirty minutes for the focus phase, thirty minutes for the act phase, and one hour for the feedback phase to debrief the experiment. The feedback phase would require only few minutes for an up and running process.

\section{2) Execution phase run}

The decision-making process experiment execution was performed in 2018 with data gathered in 2016. The objective was to compare decisions that could have been made using this approach with actual decisions that have been made between 2016 and 2018. Data were gathered resulting in the use case structure described in the previous section and Table 3. Then, the Python ${ }^{\mathrm{TM}}$ software has been run based on the collected data. It generated resource utilization and financial KPIs that supplied the preconfigured Tableau ${ }^{\circledR}$ software dashboards. Finally, dashboards have been analyzed and adjusted for the decision-making meeting. For example, the dashboard shown in Figure 3 focuses on a robustness analysis of the supply network regarding the risks of demand variation by plus or minus 25 percent. Another example is the dashboard on Figure 2 explained in the previous subsection. Other dashboards were specifically focused on an opportunity of switching the packaging of a product family from a technology to another. The objective was to visualize the impact on company's performance to be able to make a more informed decision.

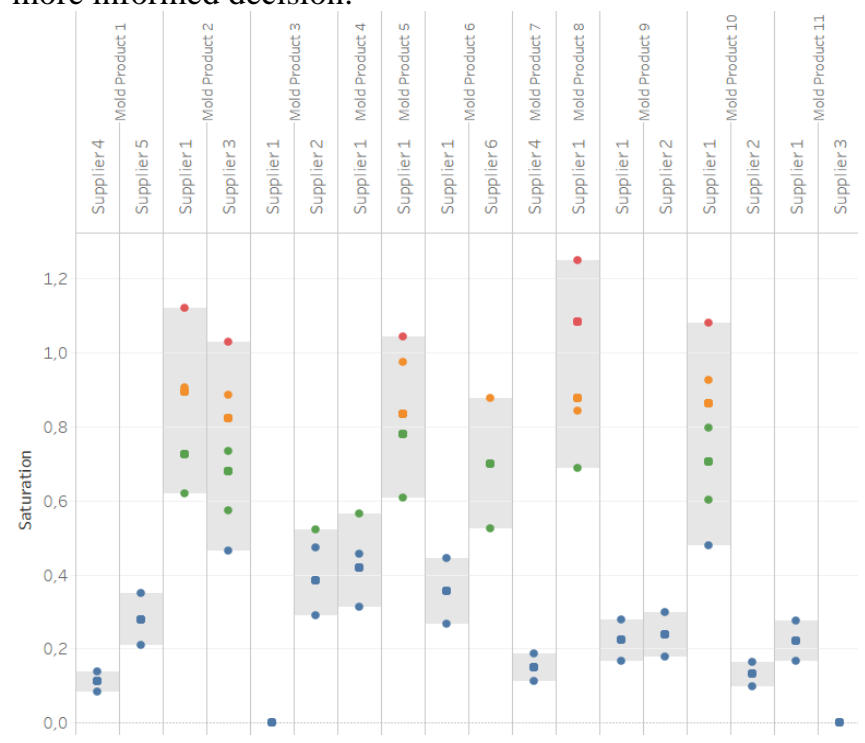

Figure 3: partial dashboard showing the resource utilization ratio intervals several scenarios of potential demand variation for each equipment category at each supplier

During the scan-focus-act phases of the decisionmaking meeting, the prepared dashboards have been presented by the process manager and 5 major risks have been identified by all stakeholders. These risks are listed in Table 4. Considering these risks, stakeholders suggested potential actions that could be performed to prevent or mitigate the risks. Then, during the feedback phase, stakeholders revealed if the action was undertaken during the last two years or not. It resulted in the last two columns of Table 4. 


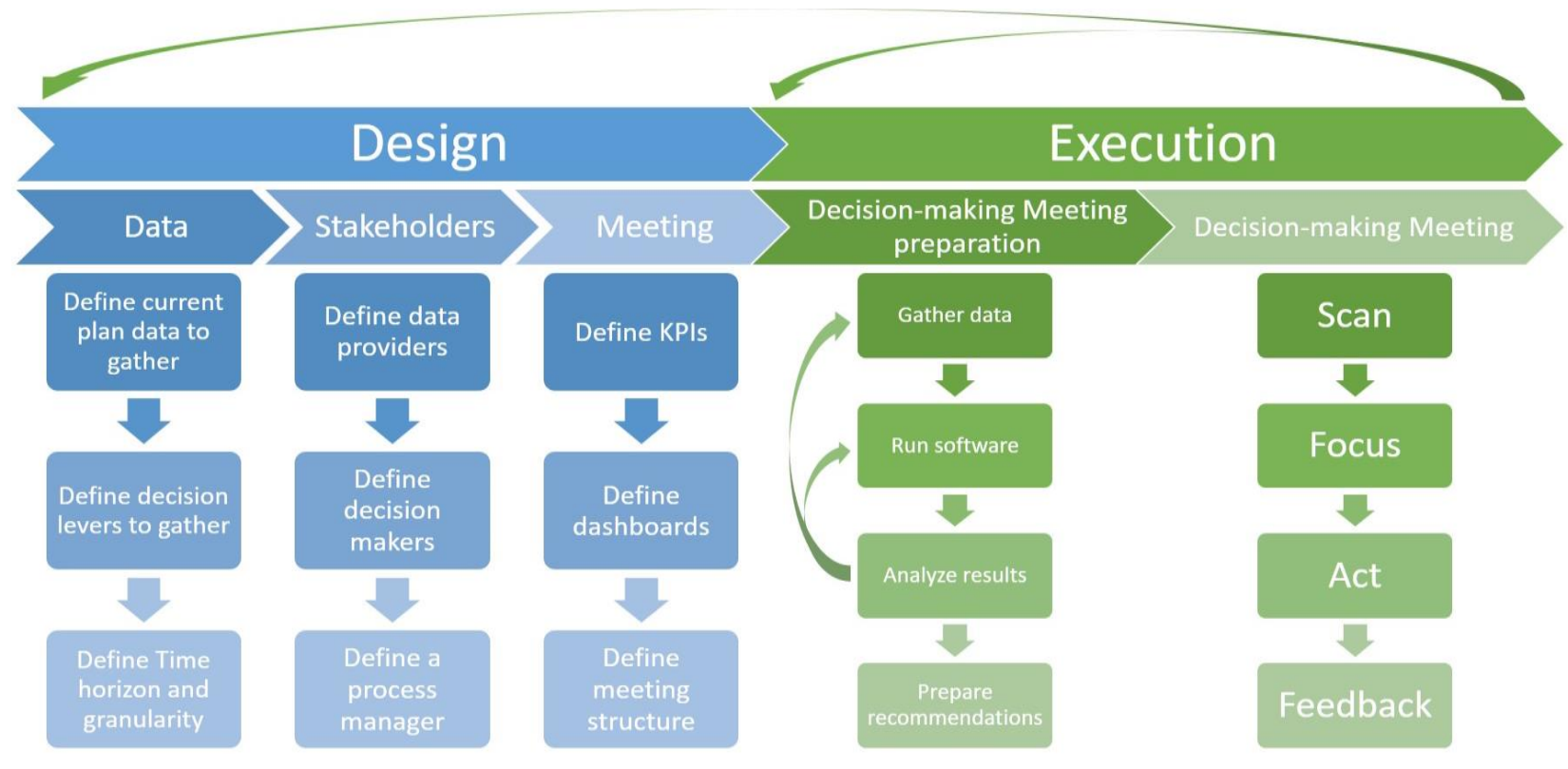

Figure 4: decision-making process created and applied for the experiment

Table 3: decision-making process stakeholders, data, and decision levers part of the industrial use case considered

\begin{tabular}{|c|c|c|c|}
\hline Department & Stakeholders & Decision levers & Data* \\
\hline Purchasing & $\begin{array}{l}\text { - Department director } \\
\text { - Buyer }\end{array}$ & $\begin{array}{l}\text { - Supplier selection } \\
\text { - Extra capacity negotiation } \\
\text { with suppliers } \\
\text { - Search for new suppliers }\end{array}$ & $\begin{array}{l}\text { - Suppliers' know-how } \\
\text { - Suppliers' capacities } \\
\text { - Supply quotas } \\
\text { - Time required to set up a new } \\
\text { mold at a supplier }\end{array}$ \\
\hline Operations & \multicolumn{2}{|l|}{$\begin{array}{l}\text { - Supply chain director } \\
\text { - S\&OP manager }\end{array}$} & - Demand \\
\hline Finance & \multicolumn{2}{|l|}{ - Financial controller } & $\begin{array}{l}\text { - Costs per unit } \\
\text { - Revenues per unit }\end{array}$ \\
\hline $\begin{array}{l}\text { Product packaging } \\
\text { development }\end{array}$ & - Department director & - Technology choices & - Product development plan \\
\hline Performance improvement & $\begin{array}{l}\text { - Department director } \\
\text { - Project manager }\end{array}$ & - Projects priorities & $\begin{array}{l}\text { - Performance improvement } \\
\text { projects plan }\end{array}$ \\
\hline Quality insurance & $\begin{array}{l}\text { - Department director } \\
\text { - Packaging quality manager }\end{array}$ & $\begin{array}{l}\text { - Quality improvement } \\
\text { negotiation with suppliers }\end{array}$ & - Suppliers' reliability \\
\hline \multicolumn{2}{|c|}{ Risk } & \multicolumn{2}{|c|}{$\begin{array}{c}\text { Additional actions that could have been performed having } \\
\text { the software proposal two years ago }\end{array}$} \\
\hline \multicolumn{2}{|c|}{$\begin{array}{l}\text { Important increase of volume of a technology at } \\
\text { one supplier }\end{array}$} & \multicolumn{2}{|c|}{$\begin{array}{l}\text { - Investigate capacity solutions such as supply quotas } \\
\text { modifications or finding a new supplier. }\end{array}$} \\
\hline \multicolumn{2}{|c|}{$\begin{array}{l}\text { A bottle family has a resource utilization ratio } \\
\text { above } 100 \text { percent for the entire supply network }\end{array}$} & \multicolumn{2}{|c|}{$\begin{array}{l}\text { - Investigate solutions such as capacity investments or finding a } \\
\text { new supplier. }\end{array}$} \\
\hline \multicolumn{2}{|c|}{$\begin{array}{l}\text { A bottle family has a forecasted utilization ratio } \\
\text { above } 80 \text { percent }\end{array}$} & \multicolumn{2}{|c|}{$\begin{array}{l}\text { - Investigate capacity solutions such as supply quotas } \\
\text { modifications, capacity investments, or finding a new supplier. }\end{array}$} \\
\hline \multicolumn{2}{|c|}{ Three molds have a very high criticality indicator } & \multicolumn{2}{|c|}{$\begin{array}{l}\text { - Investigate capacity solutions such as supply quotas } \\
\text { modifications, capacity investments, or finding a new supplier. } \\
\text { - Investigate agility solutions such as solutions to reduce the } \\
\text { time required to set up a new mold. }\end{array}$} \\
\hline
\end{tabular}

\section{DISCUSSION AND AVENUES FOR FUTURE RESEARCH}

This paper described an experiment aiming to evaluate a process to support companies in making strategic supply chain planning decisions being aware of risks. The process includes the use of a computerized information system composed of two elements: first, a software to support computations. Second, a business intelligence software to gather company's stakeholders around a common vision of the interrelationships between decision levers and business performance. This process was put in practice on a pilot use 
case with two years old data. It resulted in the identification of several decisions that could have been made if the decision-making process was in operation two years ago. This additional information enhancing decision-makers' vision is considered as a first validation of the approach. Industrial stakeholders' feedbacks highlighted three major breakthroughs for their decision-making practices: first, the ability to automatically run computations required to provide information to support decisions. Second, the ability to oversee interdependencies between departments decisions and with the whole company's performance. Third, the ability to oversee the sensibility of their supply network regarding risks so to evaluate its robustness.

In addition of the positive feedbacks, some limitations were identified. The major limitations were about input data: first, the time required to gather data is long, both internally and about the supply network. Second, data quality is sometimes difficulty to evaluate. To overcome these limitations, an innovative approach is under development to integrate supply chain hyperconnectivity and event-driven principles [21]. This approach is composed of two pillars: first, the detection of evolutions impacting previously established supply chain plans. Second, the adaptation of the supply chain plans.

\section{ACKNOWLEDGMENT}

The authors acknowledge IMT Mines Albi's Pierre Fabre Chair in Agile Supply Chain and Georgia Tech's Coca-Cola Chair in Material Handling and Distribution for the funding of this research.

\section{REFERENCES}

[1] H. Stadtler, C. Kilger, and H. Meyr, Eds., Supply Chain Management and Advanced Planning: Concepts, Models, Software, and Case Studies, 5th ed. Berlin Heidelberg: Springer-Verlag, 2015.

[2] International Organization for Standardization, ISO Guide 73:2009 Risk management -- Vocabulary. 2009.

[3] E. Simangunsong, L. C. Hendry, and M. Stevenson, "Supply-chain uncertainty: a review and theoretical foundation for future research," International Journal of Production Research, vol. 50, no. 16, pp. 4493-4523, Aug. 2012.

[4] International Organization for Standardization, ISO 31000:2018 Risk management -- Guidelines. 2018.

[5] U. R. de Oliveira, F. A. S. Marins, H. M. Rocha, and V. A. P. Salomon, "The ISO 31000 standard in supply chain risk management," Journal of Cleaner Production, vol. 151, pp. 616-633, May 2017.

[6] R. Bhatnagar and A. S. Sohal, "Supply chain competitiveness: measuring the impact of location factors, uncertainty and manufacturing practices," Technovation, vol. 25, no. 5, pp. 443-456, May 2005

[7] International Organization for Standardization, ISO 31000:2009 Risk management -- Principles and guidelines. 2009.

[8] B. M. Beamon, "Supply chain design and analysis: Models and methods," International journal of production economics, vol. 55, no. 3, pp. 281-294, 1998.

[9] M. Goetschalckx, C. J. Vidal, and K. Dogan, "Modeling and design of global logistics systems: A review of integrated strategic and tactical models and design algorithms," European Journal of Operational Research, vol. 143, no. 1, pp. 1-18, Nov. 2002.

[10] M. J. Meixell and V. B. Gargeya, "Global supply chain design: A literature review and critique," Transportation Research Part E: Logistics and Transportation Review, vol. 41, no. 6, pp. 531-550, Nov. 2005.

[11] J. Pires Ribeiro and A. Barbosa-Povoa, "Supply Chain Resilience: Definitions and quantitative modelling approaches - A literature review," Computers \& Industrial Engineering, vol. 115, pp. 109-122, Jan. 2018.
[12] X. Chen, Y.-S. Ong, P.-S. Tan, N. Zhang, and Z. Li, “Agent-based modeling and simulation for supply chain risk management-a survey of the state-of-the-art," in Systems, Man, and Cybernetics (SMC), 2013 IEEE International Conference on, 2013, pp. 1294-1299.

[13] S. Prakash, G. Soni, and A. P. S. Rathore, "A critical analysis of supply chain risk management content: a structured literature review," Journal of Advances in Management Research, vol. 14, no. 1, pp. 69-90, Feb. 2017.

[14] P. Singhal, G. Agarwal, and M. L. Mittal, "Supply chain risk management: review, classification and future research directions.," International Journal of Business Science \& Applied Management, vol. 6, no. 3, 2011.

[15] R. Oger, M. Lauras, B. Montreuil, and F. Benaben, "Enabling Supply Chain Agility and Resilience Improvement: Toward a Methodology and Platform," presented at the IFAC 2017 World Congress, Toulouse, FRANCE, 2017.

[16] R. Oger, F. Benaben, M. Lauras, and B. Montreuil, "Towards Decision Support Automation for Supply Chain Risk Management among Logistics Network Stakeholders," IFAC-PapersOnLine, vol. 51, no. 11, pp. 1505-1510, 2018.

[17] E. Brandon-Jones, B. Squire, C. W. Autry, and K. J. Petersen, "A Contingent Resource-Based Perspective of Supply Chain Resilience and Robustness," J Supply Chain Manag, vol. 50, no. 3, pp. 55-73, Jul. 2014.

[18] A. Clément et al., "Robustesse, résilience: une brève synthèse des définitions au travers d'une analyse structurée de la littérature," presented at the MOSIM'18 - 12ème Conférence internationale de Modélisation, Optimisation et SIMulation, 2018, p. 8 p.

[19] "Tableau: Business Intelligence and Analytics Software." [Online]. Available: https://www.tableau.com/. [Accessed: 24-Feb-2019].

[20] MG Taylor Corporation, "Scan Focus Act," 1996. [Online]. Available: http://legacy.mgtaylor.com/mgtaylor/glasbead/SFA.htm. [Accessed: 26-Feb-2019].

[21] R. Oger, B. Montreuil, M. Lauras, and F. Benaben, "Towards Hyperconnected Supply Chain Capability Planning: Conceptual Framework Proposal," presented at the 4th International Physical Internet Conference, Groningen, THE NETHERLANDS, 2018. 